darbieten, welcher sich auch ferner noch besonders dadurch auszeichnet, dafis er an der Luft verharzt uud dies, wie es scheint, in um so stïkeren Grade, in welchem die Benzoesiiure aus ihrer Auflösung verdamplt. - habe ich mich nicht des Gedanlens erwehren können, dals dieser Körper nur eine Art von bxtractivstofl mit sauren Eigenschaften sei, welcher die Fihigkeit besitze, die erwähnten Reactionen auf Fisell-, Kupferund Silbersal\%e in Verbindung mit den Alkalien hervorzubringen. Dieser Körper möchte sich danı forlwährend, indem die Benzuesäure ein Product seiner Zerlegung wäre, in Harz verwandeln, neben jeser ist aber auch noch der durch $\Lambda$ lkalien in der Farbe veränderliche Körper, welchen wir zuletzt noch bei der Sublimation die Benzoesiure begleiten sehen, ein Product seiner Zerlegnny.

Schliefslich erlatube ich mir noch zu erwïhnen, dafs ich den lirystallinischen Körper, welchen La n de rer beubachtet haben will, trotz der von ihm geschilderten sauren Reaction, (welche aber vielleicht, durch an der Luft gesinerten Alkohol bedingt worden ist) und mancher anderen Controverse fuir nichts anderes halte, als fïr Ilary, welches sich aus der Tinctur bei langsamen Verdunsten des Alkohols abgesetzt hat. Zur Rechtfertigung dieser Meinung bitte ich nur um Beobachtung des Rückstandes, welcher bleibt, wenn z. B. einige Tropfen Guajakholztinctur, langsam an einem Glase, (welches mit der Tinctur gefüllt und eben gebraucht worden ist) hinablaufend, verdunsten.

\title{
Ueber die Producte der Einwirkung der Salpetersäure auf Aloe; von A. Boutin.
}

Die Linwirkung der Salpetersäure auf die organischen Substanzen ist im Allgemeinen sehr intercssant; es entsteleen dadurch Producte, die schon längst die Auf- 
merksamkeit der vorzüglichsten Chemiker auf sich gezogen haben; einige dieser Producte haben die wichtigsten Anwendungen in den Künsten gefunden, andere weniger bekannte sind bis jetzt ohne Nutzen geblieben, wenn auch nicht für die Wissenschaft, doch für die Industrie. Ich wïrde mich glücklich schätzen, wenn ich der Färberei, die wir tïşlich mit den schönsten Entdeckungen sich bereicherı sehen, mich verpflichtet hätte durch die Anwendung eines neuen Farbestoffs, der bis diesen 'Tag unberücksichtigt blieb; denn weder Braconnot noch Liebigg, der nach ihm mit dieser Substanz sich beschüftigte, scheinen ihn hinlänglich rein erhalten zu haben.

\section{Einuirkung der Salpetersüure.}

Wenn man 1 Theil succotrinische Aloe und $8 \mathrm{Th}$. Salpetersäure in einem Kolben, der die 8-10fache Menge dieser Materialien fassen kann, einer mälsigen Wärme auf dem Sandbade aussetzt, so nimmt die Flüssigkeit zuerst eine schöne smaragdgrüne Farbe an, ohne dafs eine merkliche Reaction $\% u$ entstehen scheint; so wie aber die 'Tentp. steigt, wird die Flüssigkeit dunkler und braun, und es entwickeln sich viele rothe Dämpfe. Man nimmt dann die Retorte vom Sandbade, und lïfst die Reaction sich selbst fortsetzen, sie wird so lebhaft und es entwickelt sich so viel Salpetergas, dat's die ganze Masse in den Hals des Kolbens steigt.

Nach beendigter Reaction wird die Flïssigkeit in eine hinreichend geränmige und mit einem Recipienten versehene Retorte gegrelien, und ohngefähr die Hälfte oder zwei Drittel überdestillirt. Während der Destillation fällt ein gelbes Pulver nieder. Die Retorte wird nun entleert, man läfst die ganze Masse erkalten und verdünnt mit einer gewissen Quantität VVasser, wodurch sich sogleich ein neuer dem vorigen ähnlicher gelber flockiger Niederschlag bildet, den man mit dem ersten auf einem Filter sanmelt und mit warmem Wasser auswäsclit, bis die filtrirende Flüssigkeit eine sehr schöne 
purpurrothe Farbe angenommen hat, und eben so der Niederschlag; letzter wird getrocknet und erscheint als ein braunrothes Pulver. Ich werde ihn mit dem Namen Polychromatinsäure bexeichnen.

Ehe ich diese Säure näher beschreibe, werde ich kürzlich der andern Producte gedenken, die sich bei der Reaction der Salpetersäure auf die Aloe bilden. Zwei dieser Producte sind bekannt, die Oxalsäure und die Kohlenstickstoffsäure; man erhält aber noch ein drittes, welches man bisher noch nicht angefiilirt hat, und dessen Entstehung und Eigenschaften zu merkwïrdig sind, um nicht zu einem tiefern Studium desselleen und seiner Analyse aufzufordern; ich hoffe dieses in einer folgenden Arbeit auszuführen; ich habe diesem neuen Kürper den Namen Cyanil gegeben, und will nur vorläufig anführen, dafs zwischen dem Cyanil und der Cyanwasserstoffsäure in Bezug des Geruchs und der giftigen Eigenschaflen eine so grofse Analogie statt fiudet, dafs man erstes mit letzler bis auf einen gewissen Punct für isomer halten sollte.

\section{Polychromatinsäure.}

Dieser Körper wurde von Braconnot mit dem Namen Aloesäure und von Liebig mit dem Namen Aloebitter bezeichnet; er besitzt eine sehr dunkelbraunrothe Farbe, nicht eine schöne gelbe, wie Liebig anführt, er hat einen sehr bittern zusammenziehenden Geschmack, keinen merklichen Geruch, röthet das Lackmuspapier, und reigt keine krystallinische Bildung, welchem Auflösungsmittel man ihn auch aussesetzl haben mag. Bei 300 bis $400^{\circ} \mathrm{C}$. wird er augenblicklich zersetzt und schmilzt unter leichtem Detonniren. Die Producte dieser Zersetzung sind, wie Li c bi gr allgiebt, Kohlenoxydgas, Kohlensïure, Stickstoff, ülbildendes Gas, Hydrocyansiture oder Cyanil und ein sehr geringer kohliger Rüclistand. Auf eine gliiliende Kohle geworfen, schmil\%t die Polychromatinsäure und giebt nach Cyan riechende Dimpfe aus. In Wasser von gewïhnlicher Tem- 
peratur ist sie schwerlöslich, aber die geringe Menge, die sich aufogelöst hat, reicht hin, eine grofse Menge Wasser schön purpurroth za färben. Von Wasser von $100^{\circ} \mathrm{C}$. erfordert die Polychromatinsäure $856 \mathrm{Th}$. zur $\Lambda$ uflösung und $70-80$ Th. Alkohol bei gewöhnlicher Temp. Von Mineralsïuren wird sie in der Wärme aufgeliist, durch Erkalten aber wieder ausgeschieden, wie Liebig anführt, sie ist aber alsdann von der auflösenden Säure imprägnirt und schön gelb. Um sie zu reinigen, reicht ein gutes Auswaschen hin. Am reinsten erhält man sie durch Sättigen mit koblensaurem Kali oder Natron, mehrmaliges Umkrystallisiren der Salze, Zersetzen mit verdünnter Chlorwasserstoffsäure, und Auswaschen des Niederschlags mit warmem Wasser. So gereinight läfst sie sich auf Platinblech ohne merklichen Rüclsstand verbrennen; mit den Metalloxyden bildet sie Salze, von denen die auflöslichen recht gut krystallisiren; viele aber sind unlöslich, alle verschiedentlich gefärbt; einige fulminiren bei einer gewissen Temperatur, aber nicht durch Stors.

Das polychromatinsaure Kali krystallisirt in kleinen prismatischen blutrothen Nadeln und hat einen zusammenziehenden schwach bittern Geschmack; in warmem Wasser ist es löslicher als in kaltem, auf einer glühenden Kohle schmilat es wie Salpeter. Ist es vollkommen rein, so wird es durch Alkohol nicht in Salpeter und cine gelbe bittere Materie zersetzt, wie Liebig angiebt; dieses beweist, dafs er die Polychromatinsäure nicht frei von Salpetersäure erlalten hatte. Das polychromatinsaure Silberoxyd krystallisirt in kleinen sehr feinen prismatischen dunkelvioletten Nadeln; in lialtem Wasser ist es fast unlöslich, in warmem leichtlöslich. Auf Kohlen fulminirt es schwach; es hesitzt keinen merklichen Geschmack und wird durch Zersetzen von polychromatinsaurem Kali mit salpetersaurem Silber dargestellt.

Nach einer von lelouxe angestellten Analyse besleht die Polychronatinsäure aus : 


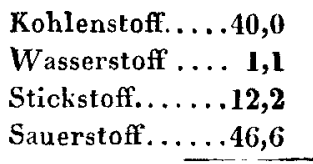

100.

Dieses würde der Formel $\mathrm{C}_{15} \mathrm{Az}_{2} \mathrm{II}_{2} \mathrm{O}_{13}$ entsprechen; doch muls diese Analyse noch wiederholt und durch die einiger polychromatinsaurer Salze controlirl werden.

Anwendung der Polychromatinsäure in der Färberei.

Die verschiedenen Nuancell, welche ich mit der Polychromatinsäure auf Seide erhalten habe, und die sich eben so gut auf Wolle befestigen lassen, werden gewil's einst von grofsem Interesse für die Färberei sein, weil sie solider sind, als alle bisher auf diese Stoffe angewandten Farben, besonders Pflanzenfarben. Die Anwendung, welche ich davon in meiner Färberei gemachi habe, sowohl mil der reinen Säure, als in Verbindungr derselben mit auderen Farbstoffen, um den Nuancen mehr Festighleit zu geben, haben mir den Nutzen bewiesen, welchen die Färberei und der Druck von dieser Substanz ziehen können, weil sie leicht darzustellen ist, und unter eimem geringen Volum eine grofse Farbekraft besitzt. Ich habe der Akademie der Wissenschaften Muster vorgelegt, die vor vier Jahren gefärbt waren und zweimal die Reise von Paris nach Petersburg gemacht. haben, ohne dafs die Wirkung des Meeres die Farbe beeinträchtigt hälle. Im Folgenden will ich das Verfahren und die Beizen zur Fixirung aller dieser Nuancen angeben.

No. 1. Die mehr oder weniger dunklern Holzfarben werden erhalten durch Beizen der Seide in einer Auflösung von essigsaurem Kupfer bei $70-80^{\circ} \mathrm{C}$. Sie wird darauf in ammoniakhaltigem Wasser gewaschen und durch ein Bad von Polychromatinsäure genommen von derselben Temp als die Beize; die Nuance wird durch verdünnte Essigsäure avivirt.

No. 2. Behufs der Corinth-Nuancen wird die Seide 
durch eine verdünnte Auflösung von Citronsäure oder Weinsteinsäure bei $40^{\circ} \mathrm{C}$. gebeizt, und daranf in ein mehr oder weniger gesättigtes Bad von Polychromatinsäure von $50-60^{\circ} \mathrm{C}$. getaucht.

No. 3. Rosen-Nuance wird auf dieselbe Veise gemacht wie die vorige, nur setzt man dem sehr schwachen Farbenbade ein wenig Alaun zu.

No. A. Die mehr oder weniger dunklen violetten Nuancen werden erhalten, wenn man dem Polychromatinsäurebade Ammoniakflüssigkeit und Essigsäure zusetzt, erst wenn das Bad reichlich violett geworden ist, muls man die Seide bei $40-50^{\circ} \mathrm{C}$. hineinbringen. Für die Seide ist es angemessen, dafs das Bad sauer ist, für Wolle aber das Gegentheil. Ich habe gefunden, dafs die Anwendung von fertig gebildetem essigsaurem Ammoniak nicht dieselben hesultate liefert; die Nuancen sind weniger schön.

No. 5. Die beiden grauen Nuancen werden dadurch fixirt, dafs man die Seide in einer warmen Auflüsung von Zinnchlorür und Manganchlorür beizt, sie dann durch Flufswasser nimmt, und daranf durch ein warmes Bad von Polychromatinsäure, dem man etwas Weinsteinsäure zugesetzt hat.

No. 6. Die blaue Farbe erhält man, wenn man dem Bade von Polychromatinsäure ein aus Zinnchlorür und Weinstein bereitetes Doppelsalz zusetzt. Das Bad wird erst violett, dann fügt man eine Auflösung von Zinnchlorür und Veinsteinsäure hinzu, alsdann reichen einige Tropfen Ammoniak hin, dafs das Bad blau wird; hierauf färbt man die Seide darin, die Farbe ist sehr fest.

No. 7. Die Fantasiefarben werden erhalten, wenn man die Polychromatinsäure bei der Siedhitze mit Ueberschurs von kaustischem Kali behandelt, dann etwas Essigsäure zusetzt, die Seide in das so zubereitete Bad eintaucht, und sie nachher durch ein angesäuertes Wasser avivirt.

No. 8. Die Avanturin-Nuancen erhält man mit der sauren Flüssigkeit von der Reaction der Salpetersäure 
300 Boutin: Producteder Einwirkung von Salpetersäure etc.

auf die Alue, nachdem zuvor die Polychromatinsäure gefällt ist. Diese Nuancen sind sehr solide.

No. 9. Gelb erhält man mit Kohlenstickstoffsäure, die auch sehr schöne Farben giebt, und besonders sehr feste auf Wolle.

No. 10. Grün wird erhalten, wenn man die durch Kohlenstickstoffsäure gelb gefärbte Seide durch das Bad No. 6. nimmt.

Ich übergehe stillschweigend eine grofse Menge anderer Nuancen, die man mit Polychromatinsïure erhalten kann, wenn man die Beizen verïndert.

\section{Cyanil.}

Dieser neue Körper entsteht, wie ich schon angeführt habe, bei der Reaction der Salpetersäure auf die Aloe, oder vielmehr auf die Polychromatinsäure. Diese Säure nämlich wird dadurch in Kohlenstickstoffsäure, Cyanil und verschiedene andere Producte verwandelt. Das Cyanil ist eine farblose Flüssigkeit, wenn man es durch Destillation über Chlorcalcium gereinigt hat; es besitzt einen starken cyanähnlichen Geruch, ist flüchtig, sein Siedepunct scheint ziemlich hoch zu sein, sein spec. Gew. gröfser als das des Wassers, es sinlt darin unter und löst sich nur sehr wenig auf. I oder 2 Tropfen Cyanil, die man in ein 8-Unzenglas giebt, das zur Hälfte mit Wasser gefüllt ist, reichen hin, der übriggen Luft solche giftige Figenschaften zu ertheilen, dars ein Vogel durch Einathmen derselben sogleich stirbt; bringt man eine sehr feine in Cyanil eben eingetauchte Röhre auf das Auge eines Vogels, so erfolgt eben so rasch der Tod. Das Cyanil ist in seiner Zusammensetzung sehr beständig; die geringe Menge, welche ich der Akademie vorlegte, bewahre ich seit zwei Jahren.

Die Kenntnirs der Zusammensetzung dieses sonderbaren Körpers wird ohre $Z_{\text {weifel }}$ zu interessanten wissenschaftlichen Resultaten führen; sie wird die Beziehungen zwischen den verschiedenen Producten festslel- 
len, die durch die Reaction der Salpetersäure auf einige organische Substanzen entstehen.

Ich habe oben bemerkt, dafs das Cyanil durch die secundïre Reaction entsteht, welche die Salpetersäure auf dic Polychromatinsäure auszuiuben scheint. Diese Ansicht ist un so zuverlïssiger, als man durch directe Behandlıng dieser Säure mit Salpetersäure, Kohlenstickstofssïure und Cyanil erhält.

Auch bei der Einwirlung der Salpetersäure auf den Indig bildet sich, wie ich gefunden habe, ebenfalls Cyanil, und wie es selhr glaublich, bei dem Ucberogang der Indigolinsäure in Kohlenstickstoffsäure; die Analyse des Cyanils würde dadurch noch interessanter werden. (Journ. de Pharm. XXVI, 185.)

\section{Bemerkung über die ätherischen Oele des Senfs und Rettigs; von}

Boutin und Fremy.

Lärst man vorsichtig Chlor durch eine tubulirte Retorte strömen, die Senföl enthält, so entstehen seidenglänzende sehr cohärente aher verflüchtignngsfähige $\mathrm{Kry}$ stalle, die in Wasser und Aether unlöslich, in Alkohol aber in allen Verhältnissen löslich sind. Kali verwandelt sie in eine harzige, in dem Alkali unlösliche Materie. An der Luft werden sie verändert und gefärbt. Durch einen Ueberschufs von Chlor werden sie in eine zähe Tlüssigkeit verwandelt und können nicht wieder hervorgebracht werden.

Kaustisches Kali in Stäcken übt auf das Senföl eine iu [serst heftige heaction aus; wenn man das Gefäls, worin beide Substanzen sich befinden, mälsig erwärmt, so entwickelt sich Wasserstoff, wie bei der Reaction dieses Alkali auf Benzoylwasserstoff, und es entsteht ein in Wasser lösliches Kalisalz. Die Säure dieses Salzes ist ölig, unlöslich in Wasser, aber löslich in Alkohol. 